\title{
A Study of the Inspection of In-Service Pile Foundation Bearing Capacity at High-Piled Wharf

\author{
Jing MENG ${ }^{a *}$, Feng-Yong ZHENG ${ }^{b}$, Yue-Song $\mathrm{LI}^{\mathrm{c}}$
}

Tianjin Research Institute for Water Transport Engineering, MOT Key Laboratory of Harbor \&Marine

Structure Safety, Ministry of Communications, Tianjin 300456,China

atks0mj@163.com

${ }^{*}$ Corresponding author

Keywords: High-Piled Wharf, Pile Foundation Bearing Capacity, Static Load Test.

\begin{abstract}
In order to adapt to the production demand, it is planned to upgrade the berths of high-piled wharf upper structure of which is severely damaged and adopt static load test to check if the bearing capacity of steel pipes in original structure can reach $6,000 \mathrm{kN}$ as required for use in newly built structure and economic and reliable purposes.
\end{abstract}

\section{Project Information}

In view of the severely damage upper structure of the high-piled wharf at certain sea port, it is planned to reform it so as to adapt it to the production demand. Since the existing steel pipe piles of the wharf appear to be in good conditions, in order to save the investment, it is hoped to make use of aforesaid existing piles in the new structure. It is, therefore, necessary to check with static load test piles to see if the axial allowable load capacity of existing steel pipe piles can attain $6,000 \mathrm{kN}^{[1]}$ and provide reference for the design unit. In accordance with related requirements, one pile is selected from $2 \#, 3 \#$ and $4 \#$ berth respectively to accept static load test. The results indicate the axial allowable load capacity of all three test piles exceeds $6,000 \mathrm{kN}$.

\section{Test Process}

\section{Test Methods and Principles [1]}

(1) Loading method and process

The loading is imposed at ten grades with max load of $6,000 \mathrm{kN}$, and each grade is equal to $600 \mathrm{kN}$. After each grade of load is imposed, the settlement of pile top is read $5 \mathrm{~min}, 15 \mathrm{~min}, 30 \mathrm{~min}$, $45 \mathrm{~min}$ and $60 \mathrm{~min}$ later and at the interval of $30 \mathrm{~min}$ thereafter. The test pile settlement is believed to be rather stable when it is within $0.1 \mathrm{~mm}$ and appeared two times continuously within each hour. In accordance with JTJ255-2002 Specifications for Testing of Pile under Static Load in Harbor Engineering, the load of next grade cannot be imposed until the pile top settlement speed tends to be stable. The loading will be stopped when the imposed load reaches the required max $6,000 \mathrm{kN}$, or the standard conditions are met (such as $40 \mathrm{~mm}$ settlement).

(2) Unloading method and process

The unloading is carried out at grades and the unloaded quantity is 2 times heavier than the loaded quantity at each grade (namely $1,200 \mathrm{kN}$ ) [2]. During the unloading, each grade of load is maintained for $1 \mathrm{~h}$. The load of next grade cannot be removed until the pile top settlement is read $15 \mathrm{~min}, 30 \mathrm{~min}$ and $60 \mathrm{~min}$ later respectively. After the load is completely discharged, the residual settlement of the pile top should be read. The single-pile vertical bearing capacity of all the test piles is determined by referring to onsite test, Q-S, S-logt and S-logQ curves resulting from the test materials, and corresponding specifications. The working principle of the stress application platform [3] is shown in Fig. 1: 


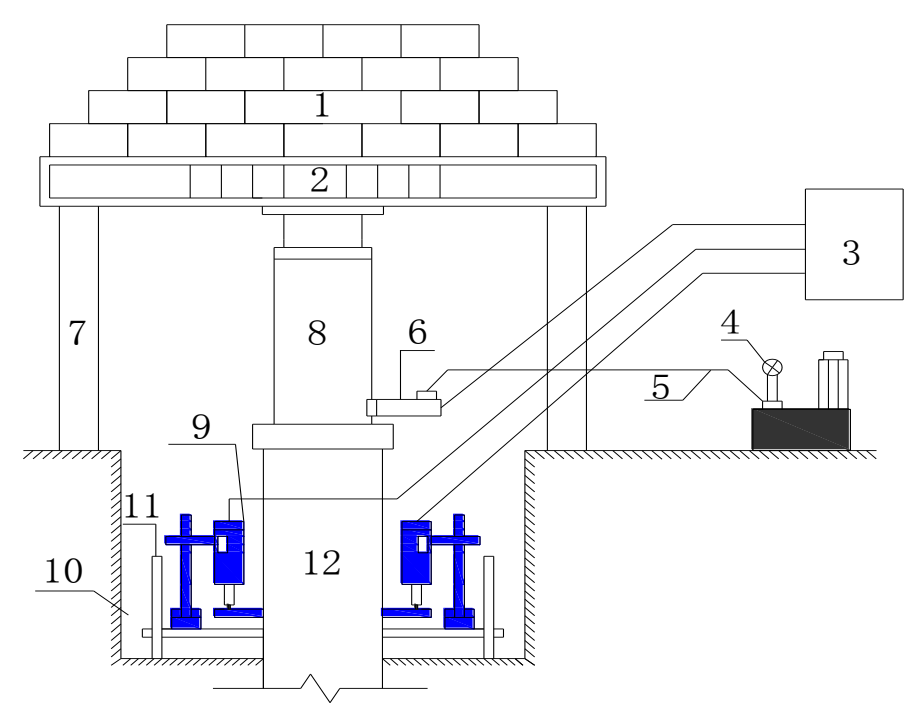

Fig. 1 Schematic diagram of stress application platform

(In it, 1-balance weight; 2-weight reaction platform; 3-JCQ tester; 4-pressure gauge; 5-high-pressure oil pump; 6-pressure sensor; 7-supporting pier; 8-jack; 9-displacement sensor; 10 - test pile; 11 -datum line beam;12- pile)

\section{Test Process and Results Analysis}

(1) Location and quantity of the test piles

There are altogether 3 test piles for the single-pile vertical allowable bearing capacity test. Their locations are shown in Fig. 2 (with boxes):

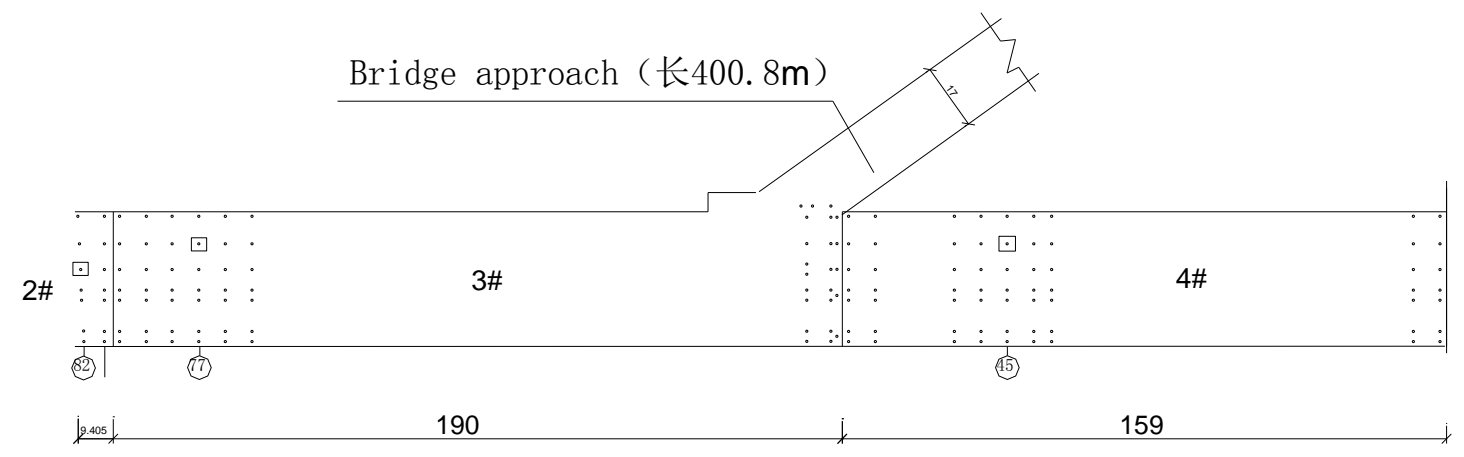

Fig. 2 Plane diagram of test pile location

\section{(2) Test process}

Test pile 2-1\# and 3-1\# accept static load test on the single pile basis after the upper structure of the wharf is removed. In view of the practical production and operation in the port, the test plan for 4-1\# test pile is changed in following aspects: the wharf beams and plates are not to be removed, and load is directly applied on the wharf surface at $4 \#$ berth pile. The application place is directly on the opposite of the test pile under the wharf, and the point supporting the ballast is placed on two bents next to the test pile. In order to reduce the centralized force on cross beam bent, one box girder is placed on the wharf surface where two bents are located, and the girder is strictly aligned with the cross beam below the panel. The reference piles are located on both sides of the test pile load application point at the distance of $7 \mathrm{~m}$. The pile top settlement test points are symmetrically arranged on both sides of the load application point. Since the compressed deformation of beams and plates at the top of test pile is negligible, the observed settlement value can be viewed as the settlement of pile top. As for the load value on the test pile top, the stress on 4-1\# test pile can be figured out with two steel-wire strain meters or force gauges mounted in symmetry at the top of the test piles according to the analogy under same conditions and stress and strain relations measured from all the piles. In this way, it is possible to know the max stress of test pile through the static 
load test on panel and determine the axial force borne by the test pile. Then finite element analysis is utilized to build corresponding model for the wharf structure within 4-1\# test pile region, and figure out the effect of upper structure on the test pile stressing so as to testify the axial force on test pile. It turns out that the consistency is quite satisfactory. The static load on 4-1\# foundation pile is illustrated in Fig. 3.

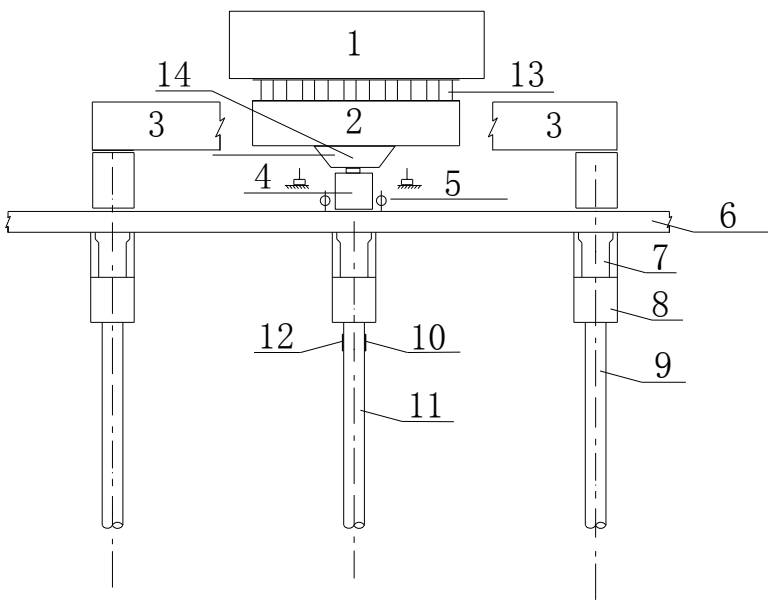

Fig. 3 Static load on 4\# berth wharf foundation pile

(In it, 1-Ballast weight; 2-Main beam; 3-Support beam; 4-jack; 5-displacement sensor; 6-Panel and surface; 7-beam; 8-Pile caps; 9-Pile; 10-Strain gage; 11-Test Pile;12 — Strain gage;13 - Cantilever beam;14-Backing)

Since the upper structure of 4-1\# test pile is not completely removed, the 4-1\# test pile bearing capacity test is not a single-pile bearing capacity test in a strict sense, but one bearing capacity test of in-service structure pile. Such auxiliary means as pile body stress detection, settlement detection and finite element structure model calculation are used to infer the actual axial force on the pile body and provide basis for the load application suspension. The pile body's cross section is made of composite materials: steel pipe pile and pile core concrete, thus it is hard to determine the elasticity modulus. We combine the parallel comparison with theoretical calculation to know the axial force on the pile body: during the static load test of 2-1\# and 3-1\# pile, two steel-wire stress gauges are mounted symmetrically $1 \mathrm{~m}$ from the pile top on both sides to measure the relation between the imposed load and stress value. The integrated test data of those two piles are be used to guide the ballast test of the 4-1\# pile. As revealed by the tests, when the load on 2-1\# and 3-1\# test pile reaches $6,000 \mathrm{kN}$, the integrated strain of the pile body is about $320 \mu \varepsilon$. Since $4-1 \#$ pile has the same cross section and materials as those two piles, it can be inferred that when the strain on 4-1\# pile reaches $320 \mu \varepsilon$ or so, the axial force will also reach $6,000 \mathrm{kN}$. In addition, according to the calculating results with finite element structure, due to the effect of upper beams and plates' structural stiffness, the axial force on test pile will not reach $6,000 \mathrm{kN}$ until $7,400 \mathrm{kN}$ is imposed on the wharf surface at pile top. Likewise the loading and observation are conducted by strictly complying with related specifications; the measured results are basically consistent with the finite element analysis.

In the loading process for three test piles, the pile top settlement does not exceed $40 \mathrm{~mm}$ and no excessive displacement is observed. Both loading and observation in the test are quite normal.

(3) Test loading termination and measured bearing capacity determination

The upper beams and plates of 2-1\# test pile are completely removed, and the test is a single-pile bearing capacity test under standard conditions. When the load is increased to be $6,000 \mathrm{kN}$, the pile top settlement reaches $12.21 \mathrm{~mm}$, and the max load control value is attained. The residual settlement after unloading is $6.68 \mathrm{~mm}$;

The upper structure of 3-1\# test pile is not completely removed by leaving the cross beam and connecting beam connected wit the test pile cap. In order to reduce the sharing of load by beam system rigidity, the concrete above two ends of four beams connected with pile cap is chiseled, and 
the upper bending moment reinforcing steel bar is cut to form simply supported beam. In this way the test pile top is only affected by the self-weight of the beam, and this effect is taken into consideration and deducted during the loading. Therefore when the total applied load attains $6,600 \mathrm{kN}$, the pile top settlement reaches $12.65 \mathrm{~mm}$. The residual settlement after the load is removed is $5.60 \mathrm{~mm}$.

Test results of 4-1\# pile: when the load on pile top wharf surface reaches $7,200 \mathrm{kN}$, the settlement is $12.56 \mathrm{~mm}$, and the pile body strain is $325 \mu \varepsilon$. In view of the safety of the wharf structure as well as the fact that max load on test pile reaches the specified value of $6,000 \mathrm{kNm}$, the loading process is stopped. The residual settlement after the load is removed is $4.54 \mathrm{~mm}$.

The test results of three piles prove that when the load on pile top reaches the max control value $6,000 \mathrm{kN}$, no pile reveals the extreme damage features as specified in related rules. In accordance with related specifications, the single-pile vertical allowable bearing capacity of each test pile should be no lower than $6,000 \mathrm{kN}$ and certain margin still exists.

(4)Test results and analysis

The bearing capacity test results of all the test piles are listed in Table 2, and the test pile detection data in single-pile static load test are summarized in Table 3. The Q-S, S-logt, and S-logQ test curves drafted in accordance with the test results are illustrated in Fig. 4- 6.

An integrated analysis [4] of the tests on three piles demonstrates the axial force on each test pile reaches 6,000 as specified. It can be inferred that the bearing capacity of three test piles are $2 \#$ berth, $3 \#$ berth and $4 \#$ berth exceeds $6,000 \mathrm{kN}$.

Tab. 1 Static load test pile results

\begin{tabular}{|c|c|c|c|c|c|c|c|}
\hline \multirow[b]{2}{*}{$\begin{array}{l}\text { Pile } \\
\text { No. }\end{array}$} & \multirow[b]{2}{*}{ Pile Location } & \multirow[b]{2}{*}{ Berth } & \multicolumn{2}{|c|}{ Pile Type } & \multirow[b]{2}{*}{$\begin{array}{c}\text { Bearing Capacity } \\
\mathrm{Q}_{\text {ui }}(\mathrm{kN})\end{array}$} & \multirow{2}{*}{$\begin{array}{l}\text { Qui }_{\text {Corresponding }} \\
\text { Settlement } \\
(\mathrm{mm})\end{array}$} & \multirow{2}{*}{$\begin{array}{l}\text { Residual Settlement } \\
\text { after Unloading } \\
(\mathrm{mm})\end{array}$} \\
\hline & & & $\begin{array}{c}\text { Pile } \\
\text { Diameter } \\
(\mathrm{mm})\end{array}$ & $\begin{array}{l}\text { Pile Length } \\
\text { (m) }\end{array}$ & & & \\
\hline $2-1^{\#}$ & $3 \#$ pile cap on row 82 & $2^{\#}$ & $\Phi 600$ & 34.1 & $\geq 6000$ & 12.21 & 6.68 \\
\hline $3-1^{\#}$ & 4\# pile cap on row 77 & $3^{\#}$ & $\Phi 600$ & 34.1 & $\geq 6000$ & 12.65 & 5.60 \\
\hline $4-1^{\#}$ & 4 \# pile cap on row 45 & $4^{\#}$ & $\Phi 600$ & 34.1 & $\geq 6000$ & 12.47 & 4.54 \\
\hline
\end{tabular}

Tab. 2 Summary of the single-pile vertical static load resisting test data

\begin{tabular}{cccccccccccccc}
\hline No. & Load & \multicolumn{3}{c}{ Settlement at Present } & \multicolumn{4}{c}{ Accumulated } & \multicolumn{3}{c}{ Duration of Present } & \multicolumn{3}{c}{ Accumulated Duration } \\
& & \multicolumn{3}{c}{ Grade (mm) } & \multicolumn{3}{c}{ Settlement $(\mathrm{mm})$} & \multicolumn{3}{c}{ Grade (min) } & \multicolumn{3}{c}{ (min) } \\
\multicolumn{2}{c}{ Test Pile } & $2-1 \#$ & $3-1 \#$ & $4-1 \#$ & $2-1 \#$ & $3-1 \#$ & $4-1 \#$ & $2-1 \#$ & $3-1 \#$ & $4-1 \#$ & $2-1 \#$ & $3-1 \#$ & $4-1 \#$ \\
\hline 1 & 1200 & 0.92 & 0.92 & 0.63 & 0.92 & 0.92 & 0.63 & 120 & 120 & 120 & 120 & 120 & 120 \\
2 & 1800 & 0.63 & 0.66 & 0.55 & 1.55 & 1.58 & 1.18 & 120 & 120 & 120 & 240 & 240 & 240 \\
3 & 2400 & 0.98 & 0.89 & 0.73 & 2.53 & 2.47 & 1.91 & 120 & 120 & 120 & 360 & 360 & 360 \\
4 & 3000 & 1.12 & 1.02 & 0.79 & 3.65 & 3.49 & 2.70 & 120 & 150 & 120 & 480 & 510 & 480 \\
5 & 3600 & 1.25 & 1.14 & 0.96 & 4.90 & 4.63 & 3.66 & 120 & 120 & 120 & 600 & 630 & 600 \\
6 & 4200 & 1.19 & 1.30 & 1.07 & 6.09 & 5.93 & 4.73 & 120 & 120 & 120 & 720 & 750 & 720 \\
7 & 4800 & 1.50 & 1.37 & 1.28 & 7.59 & 7.30 & 6.01 & 120 & 120 & 120 & 840 & 870 & 840 \\
8 & 5400 & 1.98 & 1.39 & 1.39 & 9.57 & 8.69 & 7.40 & 120 & 120 & 120 & 960 & 990 & 960 \\
9 & 6000 & 2.64 & 1.84 & 1.63 & 12.21 & 10.53 & 9.03 & 180 & 120 & 120 & 1140 & 1110 & 1080 \\
10 & 6600 & - & 2.12 & 1.58 & - & 12.65 & 10.61 & - & 150 & 150 & - & 1260 & 1230 \\
11 & 7200 & - & - & 1.87 & - & - & 12.48 & - & - & 120 & - & - & 1350 \\
12 & 6000 & - & - & -0.58 & - & - & 11.90 & - & - & 60 & - & - & 1410 \\
13 & 4800 & -0.15 & -1.00 & -1.09 & 12.06 & 11.65 & 10.81 & 60 & 60 & 60 & 1200 & 1320 & 1470 \\
14 & 3600 & -0.58 & -1.09 & -1.49 & 11.48 & 10.56 & 9.32 & 60 & 60 & 60 & 1260 & 1380 & 1530 \\
15 & 2400 & -1.08 & -1.40 & -1.62 & 10.40 & 9.16 & 7.70 & 60 & 60 & 60 & 1320 & 1440 & 1590 \\
16 & 1200 & -1.52 & -1.63 & -1.57 & 8.88 & 7.53 & 6.13 & 60 & 60 & 60 & 1390 & 1500 & 1650 \\
17 & 0 & -2.20 & -1.93 & -1.59 & 6.68 & 5.60 & 4.54 & 0 & 120 & 120 & 1500 & 1620 & 1770 \\
\hline
\end{tabular}



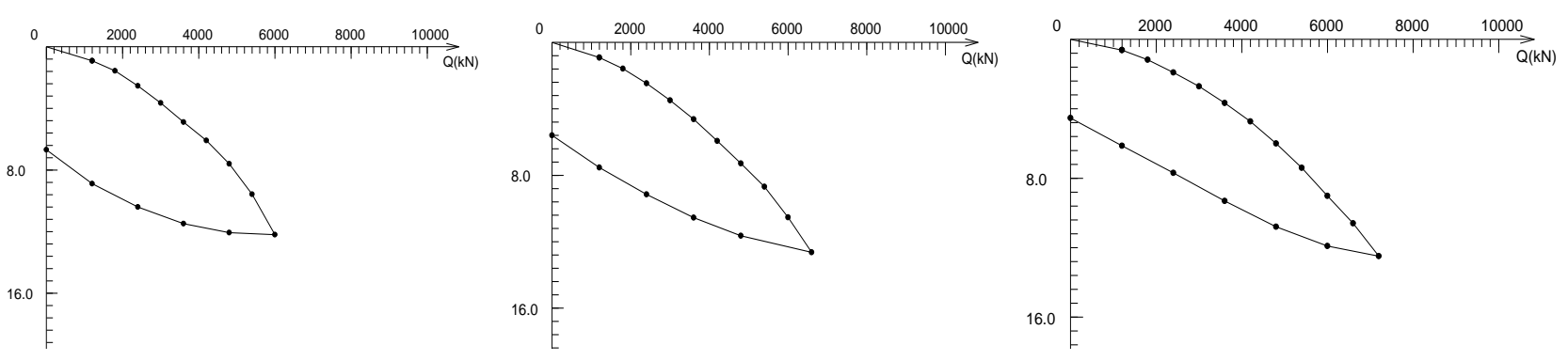

Fig. 4 Q-S Test curves of 2-1\#, 3-1\# and 4-1\# test pile

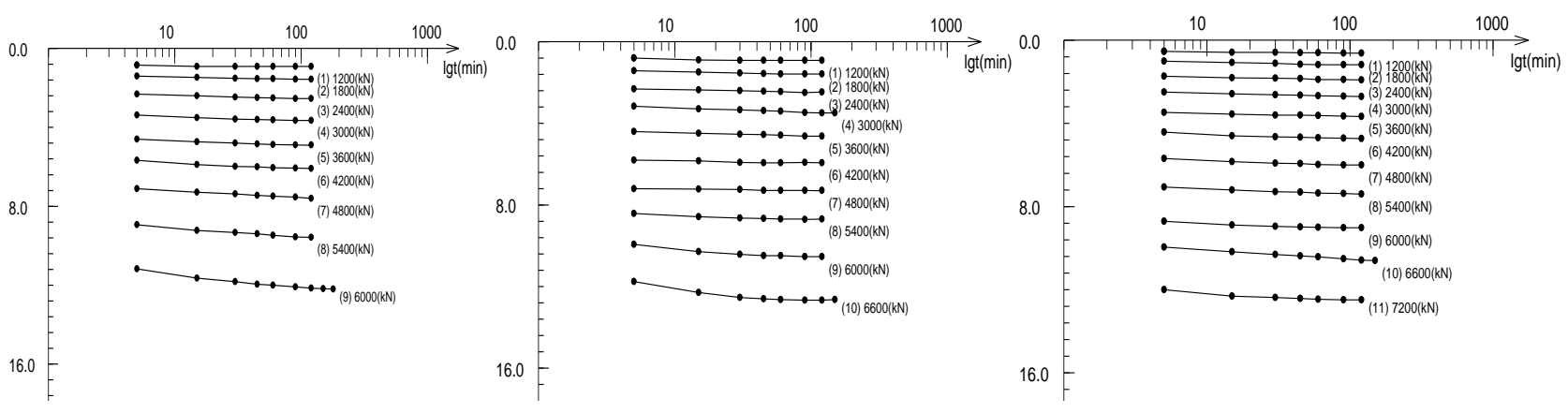

Fig. 5 S-log t Test curves of 2-1\#, 3-1\# and 4-1\# test pile
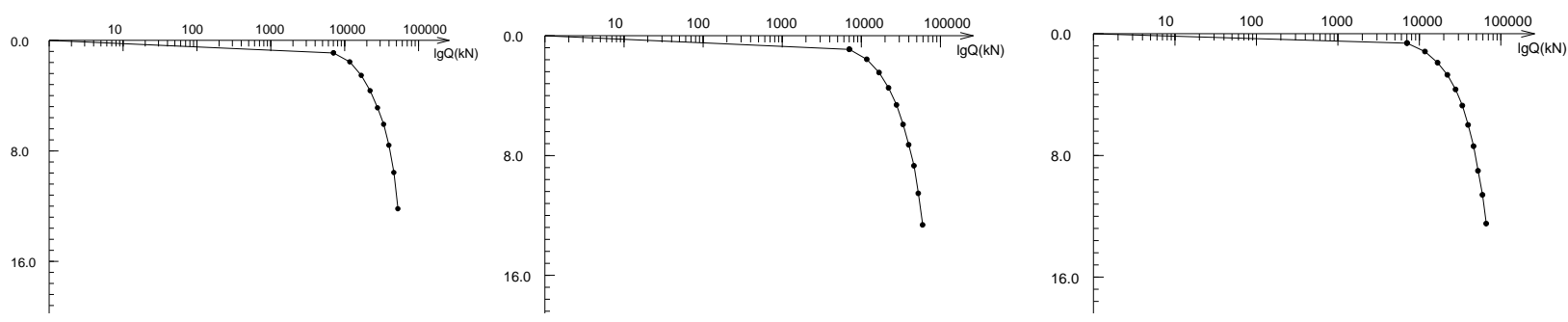

Fig. 6 S-log Q Test curves of 2-1\#, 3-1\# and 4-1\# test pile

\section{Conclusions}

Following conclusions are reached according to the onsite test results

(1)When the axial load on 2-1\#, 3-1\# and 4-1\# test piles reaches the max control value of $6,000 \mathrm{kN}$, no extreme damage property is observed after the max loading is stabilized;

(2)We can make sure with the test that the single-pile axial allowable bearing capacity of 2-1\# , $3-1 \#$ and $4-1$ \# test pile is $\geq 6000 \mathrm{kN}$;

(3)The single-pile static load test on 4-1\# pile is completed under the prototype conditions of wharf. It is verified from different aspects that its single-pile vertical allowable bearing capacity has high reference value. Due to the limited number of test piles, the test results of $2-1^{\#}$ and $3-1^{\#}$ pile are adopted while that of $4-1^{\#}$ is used as reference.

\section{Acknowledgement}

Biography: MengJing (1981-), fmale, Henan Province, Research Associate. Mainly engaged in hydraulic structure detection, diagnosis and reinforcement of Technology.

Fund Project: Central Public-interest Scientific Institutes Basal Research Fund(TKS13014)

\section{References}

[1] JTJ255-2002, Specification for Testing of Pile Under Static Load in Harbour Engineering[S].Beijing: Transport Press, 2002. 
[2] Wang Xiaobing,Kuang Qingmei. Pile Static Load Test Common Problems and Treatment Measures [J]. Jiangxi Coal Science \& Technology, 2003, P50-51.

[3] Zhang Zhiyou,Zhang Weidong. Some Reacetion Force Equipment and Thief Applications in Static Loading Test of Pile Foundations[J]. Soil Engineering and Foundation, 2002, P86-89.

[4] Chen Fan,Xun Tianping,Chen Jiu-zhao, etc. JI ZHUANG ZHI LIANG JIAN CE JI SHU[M]. Beijing: China architecture Building Press, 2003. 